\title{
ANK3 related neurodevelopmental disorders: expanding the spectrum of heterozygous loss-of-function variants
}

\author{
Katja Kloth ${ }^{1,2} \cdot$ Bernarda Lozic $^{3} \cdot$ Julia Tagoe $^{4} \cdot$ Mariëtte J. V. Hoffer $^{5} \cdot$ Amelie Van der Ven $^{1} \cdot$ Holger Thiele $^{6}$. \\ Janine Altmüller ${ }^{6}$. Christian Kubisch ${ }^{1} \cdot$ Ping Yee Billie $\mathrm{Au}^{7}$. Jonas Denecke ${ }^{8} \cdot$ Emilia K. Bijlsma $^{5}$. Davor Lessel ${ }^{1}$ (i)
}

Received: 1 May 2021 / Accepted: 20 June 2021 / Published online: 3 July 2021

(c) The Author(s) 2021

\begin{abstract}
ANK3 encodes multiple isoforms of ankyrin-G, resulting in variegated tissue expression and function, especially regarding its role in neuronal development. Based on the zygosity, location, and type, ANK3 variants result in different neurodevelopmental phenotypes. Autism spectrum disorder has been associated with heterozygous missense variants in ANK3, whereas a more severe neurodevelopmental phenotype is caused by isoform-dependent, autosomal-dominant, or autosomal-recessive loss-of-function variants. Here, we present four individuals affected by a variable neurodevelopmental phenotype harboring a heterozygous frameshift or nonsense variant affecting all ANK3 transcripts. Thus, we provide further evidence of an isoform-based phenotypic continuum underlying $A N K 3$-associated pathologies and expand its phenotypic spectrum.
\end{abstract}

Keywords ANK3 $\cdot$ Ankyrin-G $\cdot$ Isoform-based phenotypic continuum $\cdot$ Intellectual disability $\cdot$ Developmental delay

\section{Introduction}

ANK3 codes for a large ankyrin, ankyrin-G, which is integral for spectrin-actin cytoskeleton membrane stability and scaffolding [1, 2]. It plays an important role in neuronal development, cell motility, proliferation, and signaling as well as the maintenance of specialized membrane domains and the targeting of ion channels and cell adhesion molecules [3-6]. It was initially identified in neurons in the central and peripheral nervous system, namely the nodes of Ranvier and the axon initial segment (AIS) [5, 7]. Like other members of the ankyrin family, ankyrin-G consists of four functional domains: an amino-terminal domain containing multiple ankyrin-repeats, a central spectrin-binding domain, a serine-threonine-rich neurospecific domain, and a carboxyterminal regulatory death $[8,9]$.

There are multiple isoforms of ANK3 which are developmentally regulated and differentially expressed due to tissuespecific splicing $[10,11]$. Notably, three major brain-specific isoforms of $190 \mathrm{kDa}, 270 \mathrm{kDa}$, and $480 \mathrm{kDa}$ (giant AnkG) have been identified, each having a unique neuronal circuit function and distribution pattern [5, 12-15]. The 190-kDA ANK3 isoform regulates dendritic spine morphology and $\mathrm{N}$-methyl-D-aspartate (NMDA) receptor trafficking and is expressed almost ubiquitously in the brain [15]. The two bigger brain-specific isoforms sustain the myelin sheaths and play 
an important part in the formation of the nodes of Ranvier as well as the regulation of somatodendritic GABAergic synapses [12-14].

In line with its predominant neurological functions, pathogenic variants in $A N K 3$ have been linked to a broad range of neurological diseases, such as autism spectrum disorder (ASD), schizophrenia, bipolar disorder, and, more recently, intellectual disability (ID), epileptic encephalopathy, and behavioral abnormalities including a sleep and/ or attention-deficit hyperactivity disorder (ADHD) [1, 9, 16-21]. In 2017, we reported the first individual harboring a heterozygous de novo nonsense variant which affected all three $A N K 3$ isoforms who presented with mild intellectual disability, autistic, and behavioral abnormalities [21]. We and others [22] postulated an isoform-specific phenotypic continuum for missense and truncating variants affecting different brain-specific isoforms of $A N K 3$, resulting in an array of neurological features depending on the zygosity, location and type of variant, and the isoform affected [21].

Here, we present four novel heterozygous loss-of-function (LOF) variants affecting all isoforms of $A N K 3$. The highly variable severity of cognitive impairment and other symptoms in these patients further backs the claim of an isoformbased genotypic-phenotypic continuum for $A N K 3$-associated neuropathies.

\section{Materials and methods}

\section{Patient information}

All biological samples were obtained following written informed consent from studied individuals or their legal representatives. The study was performed in accordance with protocols approved by the Ethics Committee of the Hamburg Chamber of Physicians (PV 3802). The study was performed in accordance with the Declaration of Helsinki protocols.

\section{Genetic analyses}

Genomic DNA was isolated from whole blood samples using standard procedures. Whole-exome sequencing (WES) in individuals 1 and 3, and trio whole-exome sequencing (trio-WES) in individuals 2 and 4, data annotation, and interpretation were performed using methods that were described previously [23-25].

\section{Results}

\section{Patient characteristics}

Proband 1 is the first child of non-related, healthy Caucasian parents. He was born at term after an uneventful pregnancy with a slightly reduced birth weight 2790 g (3rd percentile, $-1.89 \mathrm{z})$, length $50 \mathrm{~cm}(-1.09 \mathrm{z})$, and occipitofrontal head circumference (OFC) $34 \mathrm{~cm}(-1.23 \mathrm{z})$, APGAR 10/10. At 2 years, speech delay was diagnosed. Motor development and brain MRI were unremarkable. At 5 years, the last clinical examination revealed intellectual disability (SON-IQ 55 ), speech delay (level of speech at 4.2 years at least 2 years delayed), and suspicion of ASD (not formally tested). His last body measurements were within the normal range; he showed no signs of seizures, muscular hypotonia, or spasticity. Facial dysmorphism was not reported.

Proband 2 is the first and only child of non-related, healthy Caucasian parents. He was born after an uneventful pregnancy at 39 weeks of gestation with unremarkable birth weight $3290 \mathrm{~g}(-0.45 \mathrm{z})$, length $50 \mathrm{~cm}(-0.83 \mathrm{z})$, and OFC $34 \mathrm{~cm}(-1 \mathrm{z})$, APGAR 10/10. Developmental delay became evident at 6 months. Seizures initially presented as infantile spasms, with a diagnosis of West syndrome subsequently made due hypsarrhythmia in interictal EEG. Brain MRI revealed anomalies consistent with a type 1 lissencephaly. Swallowing and breathing difficulties were accompanied by recurrent pneumonia, and he required a percutaneous endoscopic gastrostomy (PEG). At 7 years (Fig. 1a), the most recent clinical examination revealed severe global developmental delay, lack of gross, and fine motor development with involuntary repetitive stereotype movements (rotation of the whole body; flexion-extension movement of the limbs), severe axial hypotonia (no head control, nor sitting or any controlled movement), cognitive impairment, absent social eye contact, divergent strabismus, and absent speech. Seizures were recurring and EEG remained abnormal. His latest measurements showed progressive, secondary microcephaly, and mild dystrophy (head circumference $47.5 \mathrm{~cm}(-3.88 \mathrm{z})$, weight $18 \mathrm{~kg}(-2.27 \mathrm{z})$, height $117 \mathrm{~cm}(-1.38 \mathrm{z}))$. Facial dysmorphism was not reported. Fragile $\mathrm{X}$ and array-CGH analyses yielded normal results.

Proband 3 is the first child of non-related, healthy Caucasian parents. Her father passed away in an accident. She has a full sibling and two maternal half siblings who have no learning difficulties. She was born after an uneventful pregnancy at 38 weeks gestation with normal measurements. Meconium was present at delivery, APGAR 6/7. She required a 3-day NICU admission, treated for presumed infection due to apneas, poor feeding, and unstable temperature. She presented with mildly delayed motor development (unaided walking at 18 months). Although first words reportedly occurred around the first year, due to significant speech delay she received speech therapy in preschool. In kindergarten she struggled with completing tasks and understanding concepts and was subsequently home-schooled. At 13 years psychoeducational testing showed a FSIQ of 68. Autistic features were not noted but she is shy and quiet. At 14 years, she was operating at a grade 2-3 level. She had a compound 
Fig. 1 Photographs of the probands 3 and 4. a Frontal photographs of proband 3: mildly triangular face, small chin, and prominent lower lip vermilion; $\mathbf{b}$ frontal photographs of proband 4: short philtrum and thin upper lip vermillion
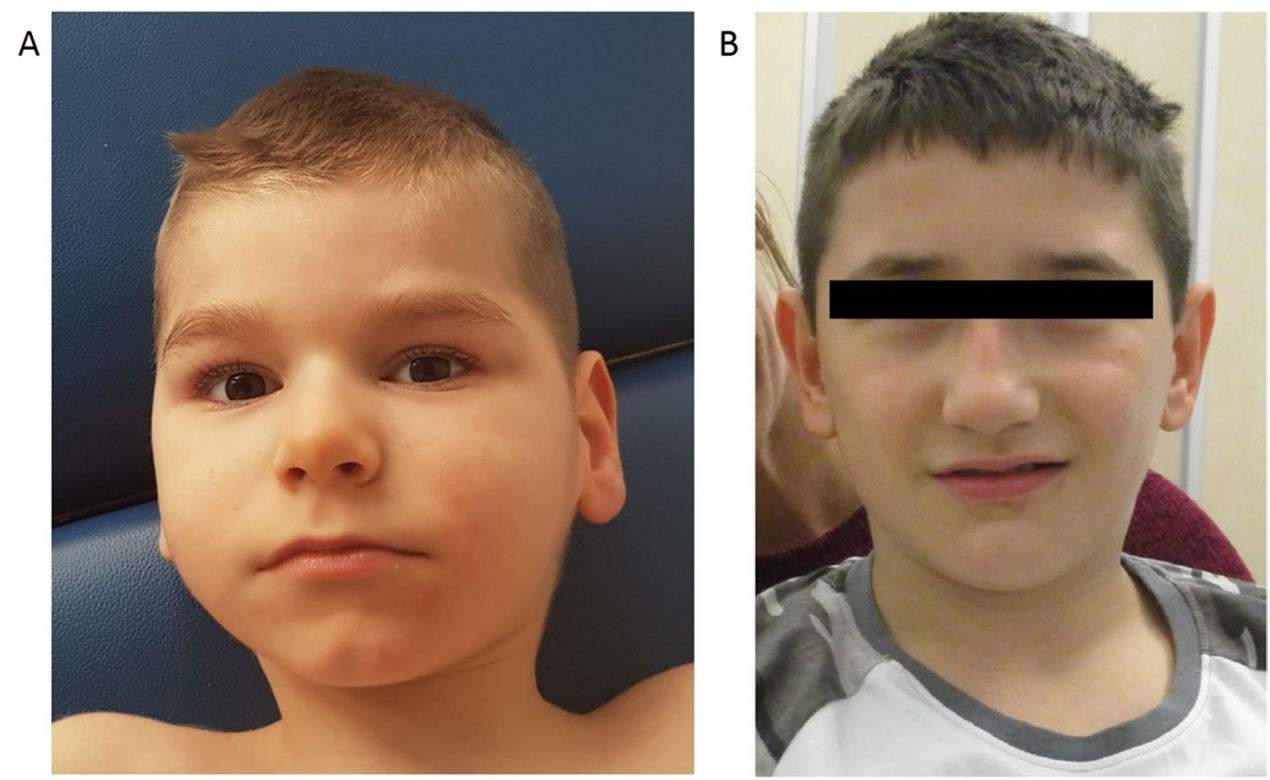

melanocytic nevus removed at age 11 years. There were no vision or hearing concerns, no history of seizures nor gait abnormality or stereotypic movements. Puberty was normal with menses starting at 12 years. Her latest clinical examination at 14 years showed an increased head circumference at $58 \mathrm{~cm}(+2.6 \mathrm{z})$ and normal weight $66.15 \mathrm{~kg}(+1.1 \mathrm{z})$ and height $169.3 \mathrm{~cm}(+1 \mathrm{z})$. A mildly triangular face, small chin and prominent lower lip vermilion were noted (see Fig. 1a). Chromosomal microarray and fragile $X$ testing were unremarkable.

Proband 4 is the second child of non-related, healthy Caucasian parents. His elder brother had mild speech difficulties and behavioral problems; genetic testing for the familial ANK3 variant was unremarkable (additional patient characteristics are given in Online Resource 1). Two paternal cousins were thought to have developmental delay, however, contact was limited and no further information could be obtained. Proband 4 was born after an uneventful pregnancy at 35 weeks of gestation. Birth measurements were unremarkable; APGAR 8/9. He initially required a feeding tube; cerebral ultrasound indicated a low-grade intracerebral hemorrhage which was not detectable in later examinations. Delayed motor development was noted at 4 months, and motor milestones continued to be delayed throughout childhood (e.g. supported sitting with 12 months, unassisted walking with 3 years). At 11 years he could run and use a tricycle (no swimming, no bicycle). Expressive and receptive language skills were profoundly impaired (active language of $\sim 10$ words) and he communicated using a language computer. Slow but continuous progress regarding verbal and motor development without signs of regression was reported. He attended special school, as writing and reading skills had not been achieved. Social interaction, sleeping and eating behavior were unremarkable. However, he displayed repetitive stereotypic movements. At the latest examination his weight was $36.6 \mathrm{~kg}(+0.1 \mathrm{z})$, body length was $131 \mathrm{~cm}(-1.9 \mathrm{z})$ and OFC was $52 \mathrm{~cm}(-1.4 \mathrm{z})$. Hearing and ophthalmologic examination, extensive laboratory work-up (including endocrine and metabolic analyses) gave normal results. His EEGs showed markers for an increased susceptibility to seizures. Brain MRI detected multiple flair hyperintensities of the white matter periventricular and hypoplastic corpus callosum. Facially, a short philtrum and thin upper lip vermillion were noted (see Fig. 1b).

\section{WES analyses}

Duo-WES with samples of the proband 1 and his mother revealed a heterozygous 1 bp-deletion in $A N K 3$, c.2050delG, p.(Leu684Ser $f * 7)$ that was absent in the mother. Trio-WES analysis in probands 2 and 4 revealed in each a novel de novo heterozygous $1 \mathrm{bp}$-deletion in $A N K 3$, c.127delG and c.3303delC, p.(Ala43Gln $\left.f s^{* 4}\right)$ and p.(Glu1102Ser $\left.f s^{* 16}\right)$, respectively. Duo-WES in proband 3 and her mother revealed a heterozygous single-nucleotide variant in $A N K 3$, c.769C $>\mathrm{T}$, p.(Arg257*), which was not maternally inherited. Paternal DNA samples of probands 1 and 3 were unavailable for testing. None of these variants were present in the gnomAD dataset v2.1.1. All four variants affected all three $A N K 3$ isoforms (Fig. 2) and likely activate nonsense-mediated mRNA decay (NMD).

\section{Discussion}

Different types of variants affecting in part different isoforms of the $A N K 3$ gene have been associated with a wide array of neurological pathologies [1, 9, 17, 18, 20-22]. A 
genotypic-phenotypic continuum for missense and nonsense mutations in ANK3 has been proposed and potentially offers an explanation for the highly variable severity of the neurological and neurodevelopmental symptoms [22]. Autosomal recessive missense variants that disturb the transition of giant AnkG from a closed to an open conformation have been identified in two individuals affected by a varied spectrum of neurodevelopmental clinical signs and symptoms [9]. Similar clinical outcome was observed in cases harboring homozygous frameshift variants that also affect only the largest 480-kDa isoform [22]. Moreover, heterozygous missense variants have been associated with a milder clinical spectrum ranging from ASD to neuropsychiatric disorders like schizophrenia and bipolar disorder [1, 16-18]. In addition, heterozygous loss-of-function (LOF) variants affecting all brain-specific isoforms of ANK3 have been identified in individuals affected by a neurodevelopmental disorder [21, 22]. Here we report four additional unrelated individuals harboring heterozygous LOF variants affecting all three major brain ANK3 isoforms. Interestingly, they display a varied spectrum of neurodevelopmental phenotypes (see Table 1).

All four presented with intellectual disability and speech delay, similar to two previously reported cases bearing similar ANK3 loss-of-function variants [21, 22]. Autistic features and delay in motor development, at least mild, were observed in three individuals. Muscular hypotonia was present in two individuals, in one of them severe. Brain MRI was conducted in two individuals: it showed type 1 lissencephaly in the most severely affected proband 2 , whereas proband 4 presented with multiple white matter hyperintensities and hypoplastic corpus callosum. Epilepsy was diagnosed in proband 2 (West syndrome), whereas proband 4 showed markers for a susceptibility to seizures on EEG without clinical seizures. Macrocephaly that we previously reported [21] was described only in proband 3, while the lissencephalic patient developed secondary microcephaly; the two other probands presented with unremarkable OFCs.

Noteworthy, proband 2 presented with the most severe clinical course of all so far known individuals harboring a LOF variant. Interestingly, p.(Ala43Gln $\left.f s^{*} 4\right)$ is the most $\mathrm{N}$-terminally located LOF variant that has been identified so far, and performed trio-WES analysis detected no other likely pathogenic variants. This variant will most likely lead to haploinsufficiency, representing a fully nonfunctional protein or null-allele. One possibility for the more severe clinical course of this individual as compared to the other ones presented here or previously [21, 22], could be that the more C-terminal nonsense and frameshift variants still result in a stable but truncated protein which does retain some of the ANK3 function. Clearly, western blot analyses utilizing proband-derived primary material, which was unfortunately not available here, are needed to clarify this. It is also worth noting that we cannot completely exclude the possibility that proband 2 harbors a further distinct genetic factor that has not been covered by WES.

However, as brain anomalies were detected in proband 4 and proband 3 had low IQ and macrocephaly, suggesting brain anomalies although brain imaging was not conducted, structural brain anomalies may represent an

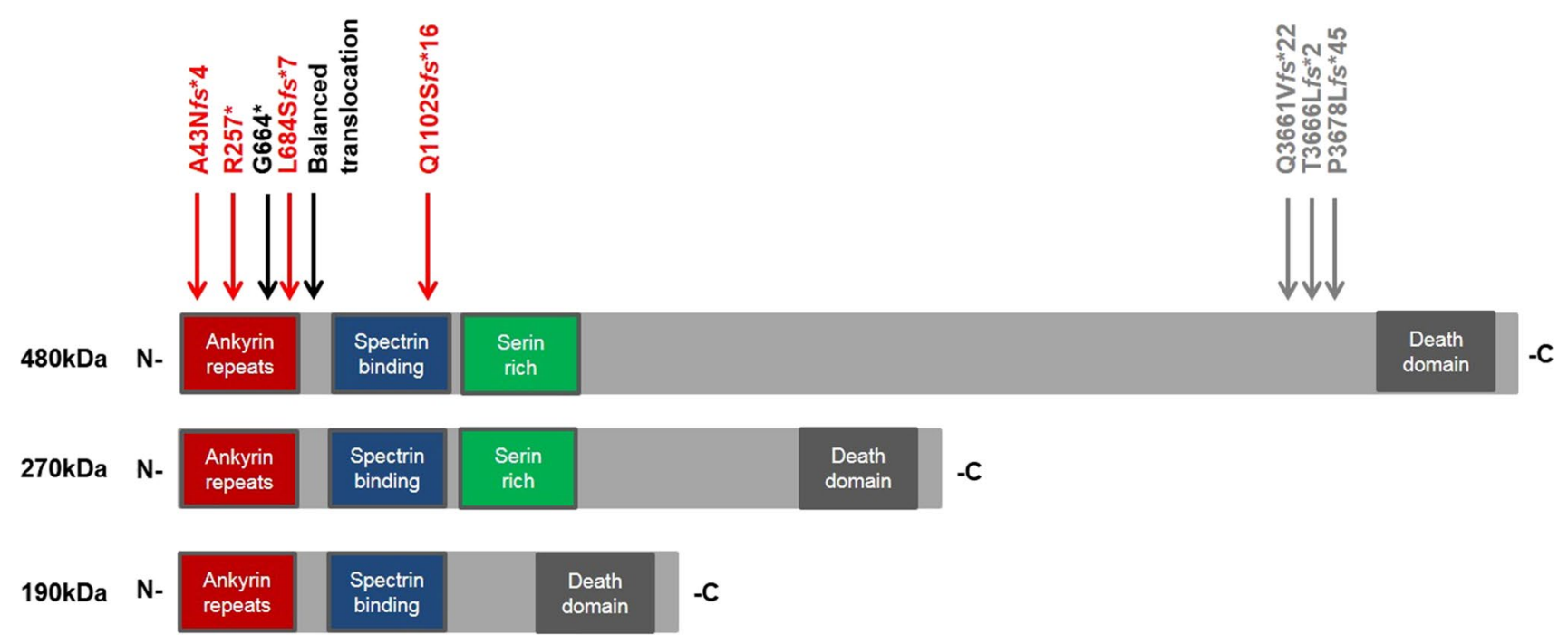

Fig. 2 Protein structure of the three $A N K 3$ isoforms with indicated positions of identified loss-of-function variants (as previously described by Kloth et al., 2017). Red arrows indicate position of the here identified heterozygous variants; black arrows indicate position of the previously reported variants affecting all three $A N K 3$ isoforms and gray arrows indicate previously reported homozygous variants affecting only a single $A N K 3$ isoform 
Table 1 Clinical features of affected individuals harboring loss-of-function variants affecting all three ANK3 isoforms (+, present; -, absent; $n / a$, unknown; $y$, years)

\begin{tabular}{|c|c|c|c|c|c|c|}
\hline $\begin{array}{l}\text { Affected indi- } \\
\text { viduals }\end{array}$ & Individual 1 & Individual 2 & Individual 3 & Individual 4 & $\begin{array}{l}\text { Previously } \\
\text { described indi- } \\
\text { vidual (Kloth } \\
\text { et al., 2017) }\end{array}$ & $\begin{array}{l}\text { Previously } \\
\text { described } \\
\text { individual (Iqbal } \\
\text { et al., 2013) }\end{array}$ \\
\hline Sex & Male & Male & Female & Male & Male & Male \\
\hline \multirow[t]{3}{*}{ Genotype } & Heterozygous & Heterozygous & Heterozygous & Heterozygous & Heterozygous & Heterozygous \\
\hline & $\begin{array}{l}\text { Not present in the } \\
\text { mother, father n/a }\end{array}$ & De novo & $\begin{array}{l}\text { Not present in } \\
\text { the mother, } \\
\text { father } n / a\end{array}$ & De novo & De novo & $\mathrm{n} / \mathrm{a}$ \\
\hline & 1 bp deletion & 1 bp deletion & Nonsense & $1 \mathrm{bp}$ deletion & Nonsense & Translocation \\
\hline $\begin{array}{l}\text { Age at last } \\
\text { examination }\end{array}$ & $5 y$ & $7 y$ & $14 \mathrm{y}$ & $11 \mathrm{y}$ & $9 y$ & $14 \mathrm{y}$ \\
\hline $\begin{array}{l}\text { Intellectual dis- } \\
\text { ability }\end{array}$ & $\begin{array}{l}+ \\
\text { IQ at the age of } 4.5 \\
\text { y: SON-IQ } 55\end{array}$ & + & $\begin{array}{l}+ \\
\text { IQ at age } 13 \mathrm{y} \text { : } \\
\quad \text { FSIQ } 68\end{array}$ & + & $\begin{array}{l}+ \\
\text { (mild) }\end{array}$ & $\begin{array}{l}+ \\
\text { (mild) }\end{array}$ \\
\hline Speech delay & $\begin{array}{l}+ \\
\text { (severe) }\end{array}$ & $\begin{array}{l}+ \\
\text { (absent speech) }\end{array}$ & $\begin{array}{l}+ \\
\text { (significant) }\end{array}$ & + & $\begin{array}{l}+ \\
\text { (mild) }\end{array}$ & + \\
\hline $\begin{array}{l}\text { Muscular hypo- } \\
\text { tonia }\end{array}$ & - & $\begin{array}{l}+ \\
\text { (severe, no head } \\
\quad \text { control) }\end{array}$ & - & + & + & + \\
\hline Spasticity & - & + & - & - & - & - \\
\hline $\begin{array}{l}\text { Stereotypic limb } \\
\text { movements }\end{array}$ & - & + & - & + & - & $\begin{array}{l}\text { - } \\
\text { (repetitive behav- } \\
\text { ior) }\end{array}$ \\
\hline Hyperactivity & - & - & - & - & + & + \\
\hline Autistic features & $\begin{array}{l}+ \\
\text { (not formally diag- } \\
\quad \text { nosed) }\end{array}$ & + & $\begin{array}{l}\text { (described as shy } \\
\text { and quiet) }\end{array}$ & - & + & + \\
\hline Epilepsy & - & $\begin{array}{l}+ \\
\text { (onset } 6 \mathrm{~m})\end{array}$ & - & $\begin{array}{l}\text { (susceptibility to sei- } \\
\text { zures on EEG) }\end{array}$ & - & - \\
\hline Aggressiveness & - & - & - & - & + & + \\
\hline $\begin{array}{l}\text { Sleeping dis- } \\
\text { order }\end{array}$ & - & - & - & - & + & + \\
\hline Chronic hunger & - & - & $\begin{array}{l}\text { Poor feeding in } \\
\text { infancy }\end{array}$ & - & + & $\mathrm{n} / \mathrm{a}$ \\
\hline $\begin{array}{l}\text { Dysmorphic } \\
\text { features }\end{array}$ & - & - & $\begin{array}{l}(+) \\
\text { Slightly triangu- } \\
\text { lar face, promi- } \\
\text { nent lower } \\
\text { lip vermilion, } \\
\text { small chin }\end{array}$ & $\begin{array}{l}(+) \\
\text { Short philtrum, thin } \\
\text { upper lip vermillion }\end{array}$ & - & $\begin{array}{l}(+) \\
\text { Flat philtrum, } \\
\text { broad nose, } \\
\text { upslanted pal- } \\
\text { pebral fissures }\end{array}$ \\
\hline Macrocephaly & - & $\begin{array}{l}\text { - } \\
\text { (microcephaly) }\end{array}$ & + & - & + & $\begin{array}{l}\text { - } \\
\text { (bordering } \\
\text { microcephaly) }\end{array}$ \\
\hline Macrosomia & - & $\begin{array}{l}\text { (feeding difficulties } \\
\text { in infancy) }\end{array}$ & - & $\begin{array}{l}\text { - } \\
\text { (feeding difficulties in } \\
\text { infancy) }\end{array}$ & + & $\mathrm{n} / \mathrm{a}$ \\
\hline cCT/brain MRI & Not done & $\begin{array}{l}\text { Type } 1 \text { lissen- } \\
\text { cephaly }\end{array}$ & Not done & $\begin{array}{l}\text { Multiple flair hyper- } \\
\text { intensities within } \\
\text { the white matter, } \\
\text { periventricular, pari- } \\
\text { etal, near the insula, } \\
\text { hypoplastic corpus } \\
\text { callosum }\end{array}$ & Normal & $\mathrm{n} / \mathrm{a}$ \\
\hline
\end{tabular}


Table 1 (continued)

\begin{tabular}{|c|c|c|c|c|c|c|}
\hline $\begin{array}{l}\text { Affected indi- } \\
\text { viduals }\end{array}$ & Individual 1 & Individual 2 & Individual 3 & Individual 4 & $\begin{array}{l}\text { Previously } \\
\text { described indi- } \\
\text { vidual (Kloth } \\
\text { et al., 2017) }\end{array}$ & $\begin{array}{l}\text { Previously } \\
\text { described } \\
\text { individual (Iqbal } \\
\text { et al., 2013) }\end{array}$ \\
\hline$A N K 3$ variant & $\begin{array}{l}\text { c.2050delG; } \\
\text { p.(Leu684Serfs*7) }\end{array}$ & $\begin{array}{l}\text { c.127delG; } \\
\text { p.(Ala43Glnfs*4) }\end{array}$ & $\begin{array}{l}\text { c. } 769 \mathrm{C}>\mathrm{T}, \\
\text { p. }\left(\operatorname{Arg} 257^{*}\right)\end{array}$ & $\begin{array}{l}\text { c.3303delC; } \\
\text { p.(Glu1102Serfs*16) }\end{array}$ & $\begin{array}{l}\text { c. } 1990 \mathrm{G}>\mathrm{T} \\
\text { p. }(\text { Gly664*) }\end{array}$ & $\begin{array}{l}\text { Balanced trans- } \\
\text { location }\end{array}$ \\
\hline
\end{tabular}

expansion of the clinical spectrum of $A N K 3$-related disorders. Thus, it might be warranted to perform singular brain scan in every individual harboring a likely pathogenic $A N K 3$ variant and to consider $A N K 3$ analysis in undiagnosed cases with structural brain anomalies. Additionally, two of the four probands presented with repetitive stereotypic movements. Since a stereotypic movement disorder (SMD) was not formally diagnosed, it remains difficult to differentiate between SMD and stereotypic autistic behavior-but stereotypic limb movements might represent a novel ANK3-related symptom. Notably, aggressiveness, hyperactivity, signs of a sleeping disorder, or chronic hunger remain unique to the individual we reported previously [21]. In line with our previous report, there were no recognizable dysmorphic features in this cohort; although mild variations of the lips, philtrum and/or chin area were described in two individuals (see Fig. $1 \mathrm{a}+\mathrm{b}$ ). Thus, as of now, we would not reliably consider these features part $A N K 3$-associated phenotype. Further clinical reports beyond the probands identified in this study are needed to elucidate the full phenotypic spectrum and broaden genotype-phenotype correlations. The latter especially holds true for the occurrence and degree of speech delay, intellectual disability, neuromuscular involvement, structural brain anomalies, epilepsy, and behavioral abnormalities.

Taken together, this cohort allows an expansion of the $A N K 3$-mediated clinical spectrum and adds further evidence to the existence of an autosomal dominant ANK3related neurodevelopmental disorder as well as an isoform-based, phenotypic continuum between dominant and recessive $A N K 3$-associated pathologies.

Supplementary Information The online version contains supplementary material available at https://doi.org/10.1007/s10048-021-00655-4.

Acknowledgements We are thankful to the affected individuals and their family members for participation.

Author contribution Conception and design of the study: D.L., K.K. Acquisition and analysis of data: K.K., B.L., J.T., M.J.V.H., A.v.d.V., H.T., J.A., C.K., P.Y.B.A., J.D., E.K.B., D.L. Drafting a significant portion of the manuscript or figures: D.L., K.K.
Funding Open Access funding enabled and organized by Projekt DEAL. This work was funded in part by Werner Otto Stiftung (to D.L) and Deutsche Forschungsgemeinschaft (LE4223/1-1 to D.L).

\section{Declarations}

Conflict of interest The authors declare no competing interests.

Open Access This article is licensed under a Creative Commons Attribution 4.0 International License, which permits use, sharing, adaptation, distribution and reproduction in any medium or format, as long as you give appropriate credit to the original author(s) and the source, provide a link to the Creative Commons licence, and indicate if changes were made. The images or other third party material in this article are included in the article's Creative Commons licence, unless indicated otherwise in a credit line to the material. If material is not included in the article's Creative Commons licence and your intended use is not permitted by statutory regulation or exceeds the permitted use, you will need to obtain permission directly from the copyright holder. To view a copy of this licence, visit http://creativecommons.org/licenses/by/4.0/.

\section{References}

1. Bi C et al (2012) Mutations of ANK3 identified by exome sequencing are associated with autism susceptibility. Hum Mutat 33(12):1635-1638

2. Bennett V, Lambert S (1999) Physiological roles of axonal ankyrins in survival of premyelinated axons and localization of voltage-gated sodium channels. J Neurocytol 28(4-5):303-318

3. Zhang X, Bennett V (1996) Identification of O-linked N-acetylglucosamine modification of ankyrinG isoforms targeted to nodes of Ranvier. J Biol Chem 271(49):31391-31398

4. Davis JQ, Lambert S, Bennett V (1996) Molecular composition of the node of Ranvier: identification of ankyrin-binding cell adhesion molecules neurofascin (mucin+/third FNIII domain-) and NrCAM at nodal axon segments. J Cell Biol 135(5):1355-1367

5. Kordeli E, Lambert S, Bennett V (1995) AnkyrinG A new ankyrin gene with neural-specific isoforms localized at the axonal initial segment and node of Ranvier. J Biol Chem 270(5):2352-9

6. Rasband MN et al (1999) Dependence of nodal sodium channel clustering on paranodal axoglial contact in the developing CNS. J Neurosci 19(17):7516-7528

7. Kordeli E, Bennett V (1991) Distinct ankyrin isoforms at neuron cell bodies and nodes of Ranvier resolved using erythrocyte ankyrin-deficient mice. J Cell Biol 114(6):1243-1259

8. Kapfhamer D et al (1995) Chromosomal localization of the ankyrinG gene (ANK3/Ank3) to human 10q21 and mouse 10. Genomics 27(1):189-191 
9. Yang R et al (2019) Neurodevelopmental mutation of giant ankyrin-G disrupts a core mechanism for axon initial segment assembly. Proc Natl Acad Sci U S A 116(39):19717-19726

10. Peters LL et al (1995) Ank3 (epithelial ankyrin), a widely distributed new member of the ankyrin gene family and the major ankyrin in kidney, is expressed in alternatively spliced forms, including forms that lack the repeat domain. J Cell Biol 130(2):313-330

11. Yamankurt $\mathrm{G}$ et al (2015) Exon organization and novel alternative splicing of Ank3 in mouse heart. PLoS One 10(5):e0128177

12. Chang KJ et al (2014) Glial ankyrins facilitate paranodal axoglial junction assembly. Nat Neurosci 17(12):1673-1681

13. Jenkins PM et al (2015) Giant ankyrin-G: a critical innovation in vertebrate evolution of fast and integrated neuronal signaling. Proc Natl Acad Sci U S A 112(4):957-964

14. Tseng WC et al (2015) Giant ankyrin-G stabilizes somatodendritic GABAergic synapses through opposing endocytosis of GABAA receptors. Proc Natl Acad Sci U S A 112(4):1214-1219

15. Smith KR et al (2014) Psychiatric risk factor ANK3/ankyrin-G nanodomains regulate the structure and function of glutamatergic synapses. Neuron 84(2):399-415

16. Athanasiu L et al (2010) Gene variants associated with schizophrenia in a Norwegian genome-wide study are replicated in a large European cohort. J Psychiatr Res 44(12):748-753

17. Codina-Sola $\mathrm{M}$ et al (2015) Integrated analysis of whole-exome sequencing and transcriptome profiling in males with autism spectrum disorders. Mol Autism 6:21

18. Epi KC et al (2013) De novo mutations in epileptic encephalopathies. Nature 501(7466):217-221
19. Ferreira MA et al (2008) Collaborative genome-wide association analysis supports a role for ANK3 and CACNA1C in bipolar disorder. Nat Genet 40(9):1056-1058

20. Sanders SJ et al (2012) De novo mutations revealed by wholeexome sequencing are strongly associated with autism. Nature 485(7397):237-241

21. Kloth K et al (2017) First de novo ANK3 nonsense mutation in a boy with intellectual disability, speech impairment and autistic features. Eur J Med Genet 60(9):494-498

22. Iqbal Z et al (2013) Homozygous and heterozygous disruptions of ANK3: at the crossroads of neurodevelopmental and psychiatric disorders. Hum Mol Genet 22(10):1960-1970

23. Lessel D et al (2018) Analyses of LMNA-negative juvenile progeroid cases confirms biallelic POLR3A mutations in WiedemannRautenstrauch-like syndrome and expands the phenotypic spectrum of PYCR1 mutations. Hum Genet 137(11-12):921-939

24. Hempel M et al (2015) De novo mutations in CHAMP1 cause intellectual disability with severe speech impairment. Am J Hum Genet 97(3):493-500

25. Lessel D et al (2020) Germline AGO2 mutations impair RNA interference and human neurological development. Nat Commun 11(1):5797

Publisher's note Springer Nature remains neutral with regard to jurisdictional claims in published maps and institutional affiliations. 